Article

\title{
Signalling and Bioactive Metabolites from Streptomyces sp. RK44
}

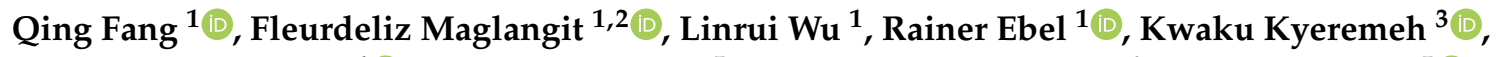 \\ Jeanette H. Andersen ${ }^{4}\left(\mathbb{D}\right.$, Frederick Annang ${ }^{5}$, Guiomar Pérez-Moreno ${ }^{6}$, Fernando Reyes ${ }^{5}(\mathbb{D}$ \\ and Hai Deng $1, *(\mathbb{D}$ \\ 1 Marine Biodiscovery Centre, Department of Chemistry, University of Aberdeen, Meston Walk, \\ Aberdeen AB24 3UE, UK; r01qf16@abdn.ac.uk (Q.F.); r01fm16@abdn.ac.uk (F.M.); \\ r031w15@abdn.ac.uk (L.W.); r.ebel@abdn.ac.uk (R.E.) \\ 2 College of Science, Department of Biology and Environmental Science, University of the Philippines Cebu, \\ Lahug, Cebu 6000, Philippines \\ 3 Marine and Plant Research Laboratory of Ghana, Department of Chemistry, University of Ghana, \\ P.O. Box LG56 Legon, Accra, Ghana; kkyeremeh@ug.edu.gh \\ 4 Marbio, UiT_-The Arctic University of Norway, N-9037 Tromsø, Norway; jeanette.h.andersen@uit.no \\ 5 Fundación MEDINA, Avda. del Conocimiento 34, 18016 Armilla, Granada, Spain; \\ freddie.annang@medinaandalucia.es (F.A.); fernando.reyes@medinaandalucia.es (F.R.) \\ 6 Instituto de Parasitología y Biomedicina "López-Neyra", Consejo Superior de Investigaciones \\ Científicas (CSIC) Avda. del Conocimiento 17, 18016 Armilla, Granada, Spain; guiomar@ipb.csic.es \\ * Correspondence: h.deng@abdn.ac.uk; Tel.: +44-1224-272953; Fax: +44-1224-272291
}

Received: 22 December 2019; Accepted: 21 January 2020; Published: 22 January 2020

\begin{abstract}
Streptomyces remains one of the prolific sources of structural diversity, and a reservoir to mine for novel natural products. Continued screening for new Streptomyces strains in our laboratory led to the isolation of Streptomyces sp. RK44 from the underexplored areas of Kintampo waterfalls, Ghana, Africa. Preliminary screening of the metabolites from this strain resulted in the characterization of a new 2-alkyl-4-hydroxymethylfuran carboxamide (AHFA) 1 together with five known compounds, cyclo-(L-Pro-Gly) 2, cyclo-(L-Pro-L-Phe) 3, cyclo-(L-Pro-L-Val) 4, cyclo-(L-Leu-Hyp) 5, and deferoxamine E 6. AHFA 1, a methylenomycin (MMF) homolog, exhibited anti-proliferative activity $\left(\mathrm{EC}_{50}=89.6 \mu \mathrm{M}\right)$ against melanoma A2058 cell lines. This activity, albeit weak is the first report amongst MMFs. Furthermore, the putative biosynthetic gene cluster (ahfa) was identified for the biosynthesis of AHFA 1. DFO-E 6 displayed potent anti-plasmodial activity $\left(\mathrm{IC}_{50}=1.08 \mu \mathrm{M}\right)$ against $P$. falciparum 3D7. High-resolution electrospray ionization mass spectrometry (HR ESIMS) and molecular network assisted the targeted-isolation process, and tentatively identified six AHFA analogues, 7-12 and six siderophores 13-18.
\end{abstract}

Keywords: AHFA; methylenomycin; MMFs; signalling molecules; Streptomyces sp. RK44; anticancer; antimalaria

\section{Introduction}

Streptomyces have been, for decades, one of the most prolific sources of pharmacologically-active compounds, contributing for more than half of the naturally-derived antibiotics that are in clinical use today, such as chloramphenicol (from S. venezuelae) [1], fosfomycin (from S. fradiae) [2], clavulanic acid (from S. clavuligerus) [3], and avermectin (from S. avermitilis) [4]. In our efforts to discover natural products, we have isolated a new bacterial strain, Streptomyces sp. RK44 from the underexplored areas of Kintampo waterfalls, Ghana, Africa [5,6]. 
Chemical profiling of the RK44 extract using high-resolution electrospray ionization mass spectrometry (HR-ESIMS) and Global Natural Product Social (GNPS) molecular network (MN) [7] showed a cluster of low molecular weight metabolites with a characteristic $250 \mathrm{~nm}$ UV absorption, suggesting that they share a common chromophore skeleton. Database dereplication using AntiBase 2017 (WILEY) and other online databases (The Natural Products Atlas, ChemSpider) [8,9] revealed that these metabolites have not been previously described in the literature [10,11].

The isolation was carried out and afforded a new metabolite $\mathbf{1}(1.0 \mathrm{mg})$. Interpretation of the spectroscopic data demonstrated that $\mathbf{1}$ is 2-alkyl-4-hydroxymethylfuran-3-carboxamide (AHFA), a new methylenomycin furan (MMF) homolog which bears an amide moiety at C-3 instead of carboxylic acid [12] in the former. MMFs are signalling molecules or autoregulators identified in 2008 in the model actinomycete Streptomyces coelicolor, which induce methylenomycin antibiotic production [10]. Examples of the well-characterized autoregulators include acylhomoserine lactones (AHLs) in Gram-negative bacteria [13] and $\gamma$-butyrolactones (GBLs) in Gram-positive bacteria of the genus Streptomyces [14,15].

Genome mining revealed that the furan-type autoregulators may be widespread in Streptomyces species [10], however, only one class of MMFs has been identified to date [12]. The discovery of this new class of 2-alkyl-4-hydroxymethylfuran-3-carboxamide signalling molecule, AHFA 1 further expanded the chemical space of the under-explored class of furan-based autoregulators, and the MMF biosynthetic machinery. Furthermore, the presence of AHFA 7-10, bearing various alkyl substituents at C-2 of the furan ring was also detected by high-pressure liquid chromatography (HPLC)-Ultraviolet (UV)-HRESIMS-GNPS analyses, but they were not isolated due to their trace quantities in the extract.

Along with AHFA 1, we also isolated known compounds, cyclo-(L-Pro-Gly) 2, cyclo-(L-Pro-L-Phe) 3, cyclo-(L-Pro-L-Val) 4, cyclo-(L-Leu-Hyp) 5, and deferoxamine E 6. Moreover, the MN analysis also identified the clusters corresponding to diketopiperazines 2-5, and siderophores 6 and 13-18.

\section{Results and Discussion}

A large-scale fermentation (6 L) of Streptomyces sp. RK44 in Modified Bennett's broth [16] was performed for seven days $\left(28^{\circ} \mathrm{C}, 180 \mathrm{rpm}\right)$. Subsequently, Diaion ${ }^{\circledR} \mathrm{HP}-20(3 \mathrm{~g} / 50 \mathrm{~mL})$ was added to the culture broth and incubated overnight under the same culture conditions. The mixture was filtered under vacuum, after which the residue consisting of the mycelium and HP-20 resin was submerged in $100 \%$ methanol $(3 \times 500 \mathrm{~mL})$ for $24 \mathrm{~h}$. The methanol extract was then decanted and concentrated under reduced pressure to give a crude extract $(5.8 \mathrm{~g})$ which was then fractionated by solid-phase extraction (SPE) using Strata ${ }^{\circledR}$ C18-E to give six fractions (S1-S6).

Dereplication of SPE extracts of RK44 using GNPS and a survey of databases (e.g., Dictionary of Natural Products, AntiBase, The Natural Products Atlas) suggested the presence of potentially new metabolites cluster in fraction S3. Consequently, S3 was selected for further purification using semi-preparative reversed-phase HPLC to yield $\mathbf{1}(1.0 \mathrm{mg})$, along with a number of diketopiperazines $\mathbf{2}(1.2 \mathrm{mg}), \mathbf{3}(2.0 \mathrm{mg}), \mathbf{4}(2.1 \mathrm{mg}), \mathbf{5}(2.3 \mathrm{mg})$, and the known siderophore, deferoxamine E 6 (3.0 mg) (Figure 1).

\subsection{Structure Elucidation}

The structures of the diketopiperazines (DKPs), cyclo-(L-Pro-Gly) 2, cyclo-(L-Pro-L-Phe) 3, cyclo-(L-Pro-L-Val) 4, and cyclo-(L-Leu-Hyp) 5, were determined by comparison of the UV spectra, molecular formulae, and a series of Nuclear magnetic resonance (NMR) spectra with literature data [17-21] (Figure S21-S24, Table S2). The configuration of 2-5 were determined by advanced Marfey's analysis, suggesting that all the proteogenic amino acids are in L-configuration (Table S4). Compound 6 was identical to the reported siderophore, desferrioxamine E 6 [22-24] (Figure S22, Table S3). 
Compound $\mathbf{1}$ was obtained as a yellow powder. The molecular formula of $\mathbf{1}$ (Figure 1) was established as $\mathrm{C}_{10} \mathrm{H}_{15} \mathrm{NO}_{3}$ by High-Resolution Electrospray Ionization Mass Spectrometry (HR-ESIMS) (calculated $[\mathrm{M}+\mathrm{H}]^{+}=198.1123$; observed $[\mathrm{M}+\mathrm{H}]^{+}=198.1125 ; \Delta=-0.5047 \mathrm{ppm}$ ), indicating 4 degrees of unsaturation (Figure S1). The UV absorption maximum at $250 \mathrm{~nm}$ found in its spectrum is a characteristic feature of MMF molecules.

Analysis of the ${ }^{1} \mathrm{H}, \mathrm{HMBC}$, and HSQC spectra revealed the presence of $1 \mathrm{sp}^{2}$ methine, 4 methylenes, 1 methyl, and 4 quaternary carbons leading to the sub-formula $\mathrm{C}_{10} \mathrm{H}_{12}$ (Table 1 ). The ${ }^{1} \mathrm{H}-\mathrm{NMR}$ spectrum in $\mathrm{CD}_{3} \mathrm{OD}$ contained signals for 12 of the 15 protons accounted by the molecular formula, suggesting three exchangeable protons. These protons were observed in the DMSO- $d_{6}$ spectrum at $\delta_{\mathrm{H}} 6.53\left(\mathrm{NH}_{2}\right)$ and $\delta_{\mathrm{H}} 4.05(\mathrm{OH})$. The remaining oxygen atom and the ${ }^{13} \mathrm{C}$ chemical shifts $\left(\delta_{\mathrm{C}} 162.1,123.1,139.1,115.8\right)$, and the number of double bond equivalents suggested the presence of a furan core in the structure, which is supported by the heteronuclear multiple bond correlations (HMBC) from $\mathrm{H}-5\left(\delta_{\mathrm{H}} 7.38, \mathrm{~s}\right)$ to $C-2\left(\delta_{C} 162.1\right), C-3\left(\delta_{C} 115.8\right)$, and C-4 $\left(\delta_{C} 123.1\right)$.

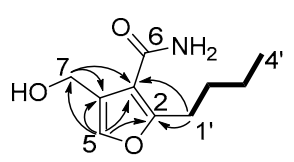

AHFA 1

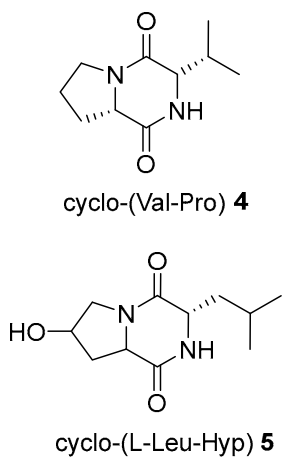<smiles>O=C1NCC(=O)N2CCCC12</smiles>

cyclo-(Gly-Pro) 2
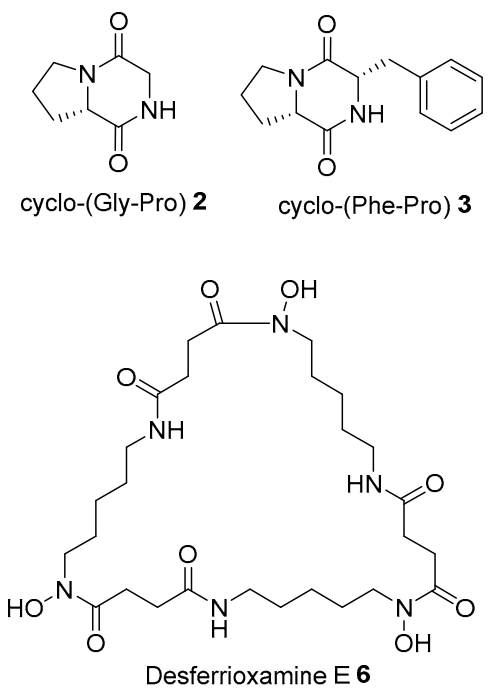

Figure 1. Isolated metabolites from Streptomyces sp. RK44. structures of which were elucidated by NMR. Structure of AHFA 1 with COSY $(-)$ and key HMBC $(\rightarrow)$ correlations.

Inspection of the ${ }^{1} \mathrm{H}-{ }^{1} \mathrm{H}$ COSY data identified one spin system from $\mathrm{H}-\mathrm{1}^{\prime}$ to $\mathrm{H}-4^{\prime}$, indicative of a butyl alkyl chain. The cross peak from $\mathrm{H}_{2}-1^{\prime}\left(\delta_{\mathrm{H}} 2.95, \mathrm{t}\right)$ to $\mathrm{C}-2\left(\delta_{\mathrm{C}} 162.1\right)$ established the connectivity of the butyl alkyl group to the furan framework. The observed downfield signal at $\delta_{\mathrm{H}} 4.52\left(\mathrm{H}_{2}-7, \mathrm{~s}\right)$ suggested a hydroxymethylene group, and it was placed at $\mathrm{C}-4$ based on the strong $\mathrm{HMBC}$ from $\mathrm{H}-7$ $\left(\delta_{\mathrm{H}} 4.52\right)$ to $\mathrm{C}-3\left(\delta_{\mathrm{C}} 115.8\right), \mathrm{C}-4\left(\delta_{\mathrm{C}} 123.1\right)$, and $\mathrm{C}-5\left(\delta_{\mathrm{C}} 139.1\right)$. The carbonyl carbon at $\mathrm{C}-6\left(\delta_{\mathrm{C}} 171.6\right)$ and the $\mathrm{N}-\mathrm{H}$ signal $\left(\delta_{\mathrm{H}} 6.53,2 \mathrm{H}\right)$ obtained in DMSO- $d_{6}$ accounted for an amide moiety, and its connectivity was assigned to the remaining quaternary carbon $C-3\left(\delta_{C} 115.8\right)$ of the furan ring.

Final structural analysis of $\mathbf{1}$ was confirmed by comparison with the spectroscopic data reported for MMF4 [12], which differs with 1 in the presence of a carboxylic acid in the former instead of the amide at position C-3. Compound $\mathbf{1}$ was therefore identified as 2-alkyl-4-hydroxymethylfruan carboxamide (AHFA). 
Table 1. NMR data of AHFA 1 in $\mathrm{CD}_{3} \mathrm{OD}$ and DMSO- $d_{6}$ at $600 \mathrm{MHz}$ and $298 \mathrm{~K}$.

\begin{tabular}{|c|c|c|c|c|}
\hline & & $\mathrm{CD}_{3} \mathrm{OD}$ & & DMSO- $d_{6}$ \\
\hline POSITION & ${ }^{13} \mathrm{C}$ (ppm) & ${ }^{1} \mathbf{H}$ (Integral, Mult.) & ${ }^{13} \mathrm{C}(\mathrm{ppm})$ & ${ }^{1} \mathrm{H}$ (Integral, Mult.) \\
\hline $4^{\prime}$ & 12.7 & $0.92(3 \mathrm{H}, \mathrm{t})$ & 13.9 & $1.01(3 \mathrm{H}, \mathrm{t})$ \\
\hline $3^{\prime}$ & 21.9 & 1.35 (2H, hep) & 21.9 & 1.41 (2H, hep) \\
\hline $2^{\prime}$ & 29.8 & $1.63(2 \mathrm{H}$, pent $)$ & 29.9 & $1.68(2 \mathrm{H}$, pent $)$ \\
\hline $1^{\prime}$ & 26.6 & $2.95(2 \mathrm{H}, \mathrm{t})$ & 26.4 & $3.03(2 \mathrm{H}, \mathrm{t})$ \\
\hline 2 & 162.1 & - & 161.3 & - \\
\hline 7 & 54.1 & $4.52(2 \mathrm{H}, \mathrm{s})$ & 54.1 & $4.53(2 \mathrm{H}, \mathrm{s})$ \\
\hline 6 & 171.6 & - & 169.9 & - \\
\hline 5 & 139.1 & $7.38(1 \mathrm{H}, \mathrm{s})$ & 138.9 & $7.64(1 \mathrm{H}, \mathrm{s})$ \\
\hline 4 & 123.1 & - & 124.2 & - \\
\hline 3 & 115.8 & - & 117.0 & - \\
\hline $\mathrm{NH}_{2}$ & - & - & - & $6.53(2 \mathrm{H}, \mathrm{br})$ \\
\hline $\mathrm{OH}$ & - & - & - & $4.05(1 \mathrm{H}, \mathrm{br})$ \\
\hline
\end{tabular}

MMFs share the common furan core in the structure, and the alkyl substituents at position C-2 of the ring can vary depending on which starter unit is incorporated during fatty acid biosynthesis [12,25]. Based on the HR ESIMS/GNPS analysis of the Streptomyces sp. RK44 extract, we have tentatively identified six AHFA 1 analogues, 7-12, with various lengths in their carbon alkyl chains at C-2 of the furan ring (Figures S10-S16, Table S1). However, they could not be isolated due to their presence in the extract in minute amounts. AHFA 7-12 clustered together in the molecular network (MN) signifying that they share a common structural motif evident in the presence of the furan framework (Figure S10). Detailed analysis of the UV pattern, MS and MS² fragmentation data showed that they exhibit the characteristic UV absorption at $250 \mathrm{~nm}$ of MMFs, and the alkyl chain substitution at position $\mathrm{C} 2$ of the ring, analogous to the MMFs that have been reported previously [12].

Further MN analysis also identified the clusters corresponding to the DKPs 2-5, deferoxamines (DFO) B and E 6 and the 2.5kDa RIPP peptide (Figure S9). The observed molecular ion peaks of 13-18 matched with the known ions in the GNPS library and they clustered together in the network, suggesting that they could be potentially new siderophores. Moreover, their fragmentation pathway were proposed based on the observed MS/MS data (Figure S20). Characterization of the peptide is currently underway in our laboratory.

\subsection{Proposed MMF Biosynthetic Gene Cluster and Pathway}

The biological function of AHFA 1 in the host cell is still unknown but is believed to be regulators of antibiotic biosynthesis in Streptomyces sp. RK44, analogous to the MMFs in S. coelicolor and GBLs in Streptomyces species [12,25]. Given the structural similarity of $\mathbf{1}$ with MMF4 [12], we predicted that $\mathbf{1}$ originated from an analogous biosynthetic pathway of MMF4. In silico analysis of the annotated RK44 genome using antiSMASH 3.0 [26] revealed one putative biosynthetic gene cluster, BGC (ahfa) that is likely to be involved in the biosynthesis of AHFA 1. Pairwise comparison of the annotated proteins using BLAST [27] and the sequence similarity network (SSN) [28] between the ahfa cluster with the $m m f$ BGC showed high amino acid identity, supporting its role in MMF homolog biosynthesis (Figure 2). 


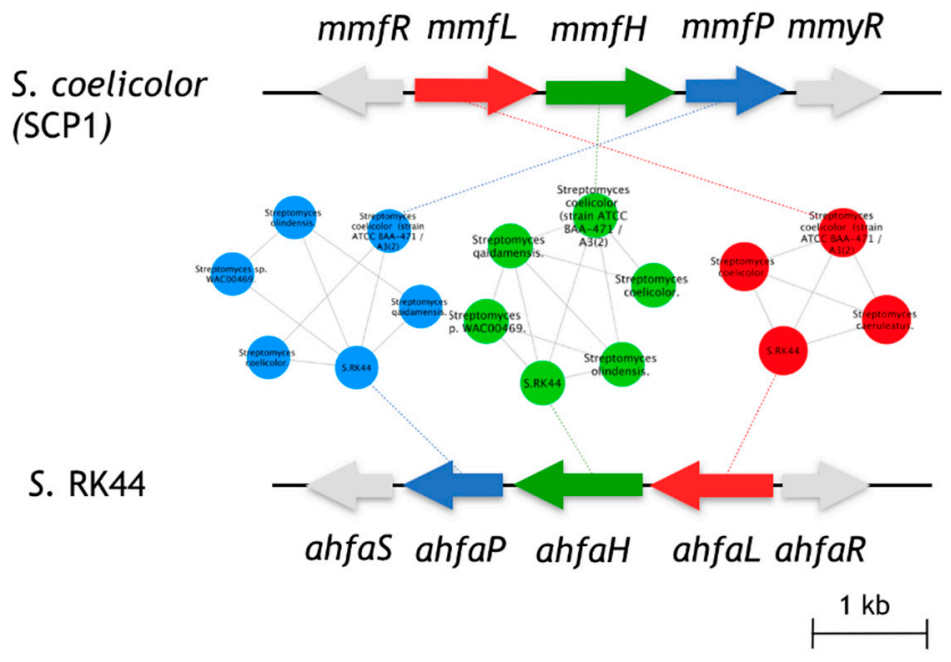

Figure 2. Comparison of the ahfa BGC in Streptomyces sp. RK44 with the mmf gene cluster on the SCP1 plasmid of $S$. coelicolor A3(2). Homologous genes are colored the same, and sequence identities between each of the encoded proteins are indicated in Table 2.

The ahfa gene cluster spans about $4.5 \mathrm{~kb}$ of genomic DNA and contains three biosynthetic genes $(a h f a \mathrm{~L}, a h f a \mathrm{P}, a h f a \mathrm{H})$ that are likely involved in the biosynthesis of AHFA 1 in Streptomyces sp. RK44 (Table 2, Scheme 1). The incorporation of stereospecifically ${ }^{13} \mathrm{C}$-labeled glycerols into the MMFs suggested that they are biosynthesized via a butenolide phosphate intermediate 22 [25], derived from the MmfL-catalysed condensation of coenzyme A $\beta$-ketothioesters 19 in fatty acid biosynthesis with dihydroxyacetone (DHAP) 20. The isotope-labelled studies indicated that the hydroxymethyl group in MMFs originated from the hydroxymethyl of DHAP, suggesting an analogous role of AhfaL to the AfsA in the biosynthesis of A-factor [29], in contrary to the alternative roles proposed by Sello and colleagues (2009) [30]. AhfaL which encodes for butenolide synthase in RK44 with 53\% identity to $m m f L$ and $42.0 \%$ similarity to $a f s a$ is proposed to catalyse a similar condensation reaction between 3-oxohexanoyl-thioester 19 and DHAP 20 to yield 21, then 22. AhfaP encoded for phosphatase and has $58 \%$ identity to $\mathrm{MmfP}$ is likely responsible for the dephosphorylation of butenolide 22 to form 23, followed by rearrangement to 24 catalysed by the flavin-dependent monooxygenase, AhfaH. The formation of the furan ring in $\mathbf{1}$ and other AHFA analogues remains elusive.
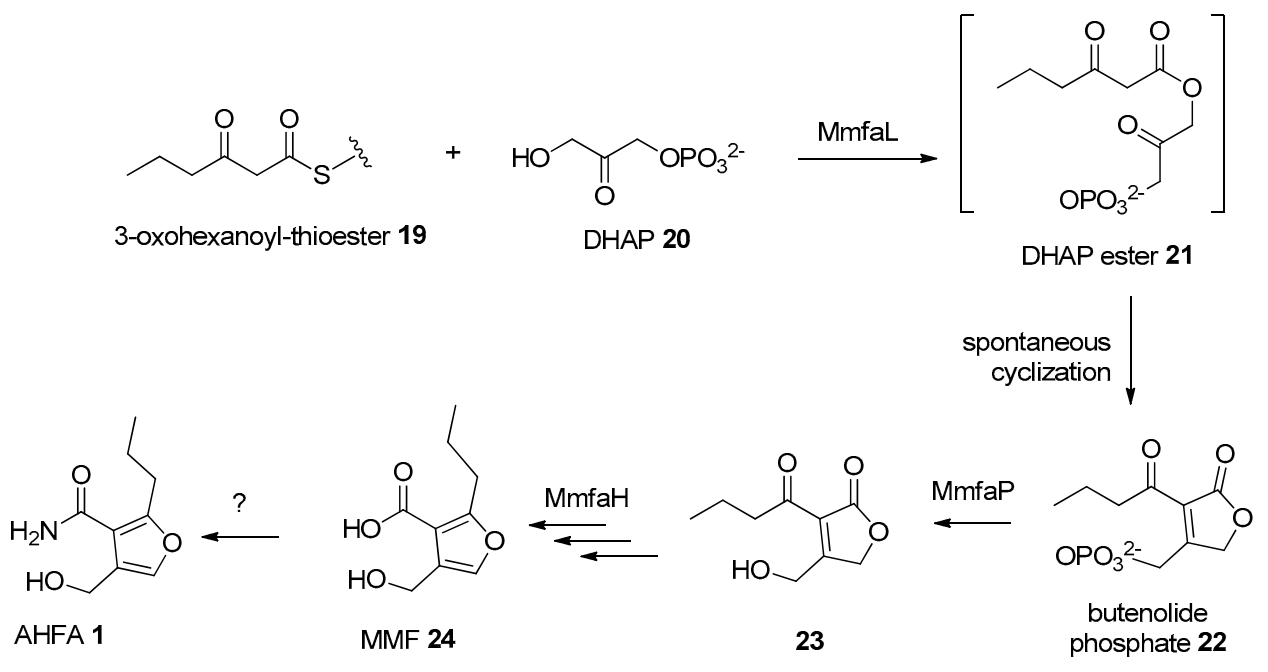

Scheme 1. Proposed biosynthesis pathway of $\mathbf{1}$. 
Furthermore, two putative genes, ahfaR and ahfaS which encode for TetR/AcR transcriptional repressor showed high amino acid identities to MmfR and MmyR (46/62, WP_011039544.1; 62/75, WP_011039548.1) in S. coelicolor [31], respectively, were likely responsible for the antibiotic regulation in RK44.

The deduced function of ahfa $L, H, P$ genes, based on their homology to autoregulatory genes ( $m m f$ or afs) of known function, supports the structure and the probable role of AHFA $\mathbf{1}$ as a signalling molecule.

Table 2. Deduced functions of open reading frames (ORFs) in ahfa biosynthetic gene cluster.

\begin{tabular}{|c|c|c|c|}
\hline Protein & AA & $\begin{array}{c}\text { Homologue } \\
\text { (\% Identity/\% Similarity) }\end{array}$ & Predicted Encoded Function \\
\hline AhfaR & 210 & $\begin{array}{l}\text { MmyR (62/75) S. coelicolor A3(2) } \\
\text { A factor receptor (30/48) S. griseus }\end{array}$ & TetR/AcR family transcriptional regulator \\
\hline AhfaP & 243 & $\mathrm{MmfP}(46 / 58)$ S. coelicolor A3(2) & Phosphatase/Hydrolase \\
\hline AhfaH & 384 & $\mathrm{MmfH}(58 / 66)$ S. coelicolor A3(2) & Oxidoreductase \\
\hline AhfaL & 334 & $\begin{array}{c}\text { MmfL (42/53) S. coelicolor A3(2) } \\
\text { AfsA (32/42) S. griseus }\end{array}$ & $\begin{array}{l}\text { Butenolide synthase/ } \\
\text { A factor biosynthesis }\end{array}$ \\
\hline AhfaS & 216 & $\operatorname{MmfR}(46 / 62)$ S. coelicolor A3(2) & TetR/AcR family transcriptional regulator \\
\hline
\end{tabular}

\subsection{Biological Test}

AHFA 1 inhibited proliferation and viability of human A2058 melanoma cells and induced anoikis $\left(\mathrm{EC}_{50}=89.6 \mu \mathrm{M}\right)$ (Figure 3B) compared to control (treated with culture media alone, Figure 3C). It is worth noting that, although weak, this activity is the first time to be reported amongst MMFs (Figure S23). Compounds 2-6 did not display any bioactivity at the highest concentration tested $(50 \mu \mathrm{M})$.
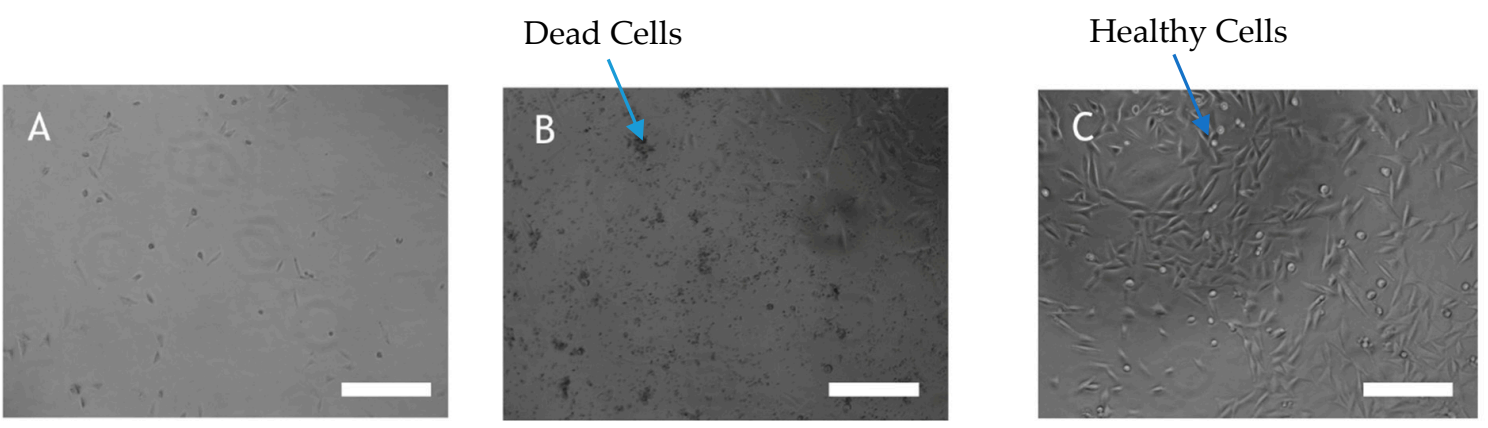

Figure 3. (A) A2058 cell treated with $50 \mu \mathrm{g} / \mathrm{mL}$ staurosporine (B) A2058 cell treated with $50 \mu \mathrm{g} / \mathrm{mL}$ AHFA 1 (C) A2058 cell treated with culture media. Cell viability was quantified by Aqueous One Solution Reagent by a colourimetric method for determining the number of viable cells in proliferation or cytotoxicity assays. A2058 cells were left untreated or were treated with AHFA $\mathbf{1}$ for $72 \mathrm{~h}$ and morphological changes of the cells were observed by light microscope (Scale bar $26 \mu \mathrm{m}$ ).

Compounds 1-6 were also investigated for their anti-plasmodial activities against Plasmodium falciparum 3D7. Only 6 showed potent antimalarial activity $\left(\mathrm{IC}_{50}=1.08 \mu \mathrm{M}\right)$, and 1-5 did not display any bioactivity at the highest concentration tested $(50 \mu \mathrm{M})$. The activity of 6 may result from the strong chelation of DFO-E 6 with iron from the culture medium of P. falciparum, causing iron deficit and finally cell death [32]. This observation was consistent with the reported antiplasmodial activities of siderophores in literature [33-36].

On the other hand, there are no significant antimicrobial activities observed in 1-6 against the Gram-negative pathogens, Pseudomonas aeruginosa ATCC 27853 and Escherichia coli ATCC 25922 at concentrations between $0-50 \mu \mathrm{g} / \mathrm{mL}$. 


\section{Materials and Methods}

\subsection{Fermentation}

Streptomyces sp. RK44 was isolated from the soil near Kintampo waterfall, Ghana, Africa. The soil isolate was streaked on an ISP2 agar plate (yeast extract $4 \mathrm{~g}$, malt extract $10 \mathrm{~g}$, glucose $4 \mathrm{~g}$, $15 \mathrm{~g}$ agar, in $1 \mathrm{~L} \mathrm{H} 2 \mathrm{O}$ ) to get pure single colonies. One single colony was inoculated into $50 \mathrm{~mL}$ of Modified Bennett's liquid medium (glycerol $10.0 \mathrm{~g}$, Oxoid yeast extract $1.0 \mathrm{~g}$, Bacto-Casitone 2.0, Lab-Lemco $0.8 \mathrm{~g}$ in $1000 \mathrm{~mL}$ MilliQ $\mathrm{H}_{2} \mathrm{O}$ ), and incubated for three days at $28{ }^{\circ} \mathrm{C}$ with shaking at $180 \mathrm{rpm}$ (Incu-shake FL16-2). This seed culture was used to inoculate $6.0 \mathrm{~L}$ of MB broth (1:100) in 12 baffled flasks (Corning $^{\mathrm{TM}}$ polycarbonate flasks), each containing autoclaved MB medium (500 mL) and plugged with Fisherbrand ${ }^{\mathrm{TM}}$ polyurethane foam stoppers (Fisher Scientific, UK). The cultures were fermented for seven days under the same condition as the seed culture. On day 7, Diaion ${ }^{\circledR} \mathrm{HP}-20$ (3 g/50 mL) was added to the fermentation culture under sterile conditions. The flasks were left in the same shaking temperature and conditions for 16-22 h. The culture broth was filtered under vacuum (Buchi pump V100, UK), and the HP-20 resin was washed with MilliQ water and extracted thrice with 100\% methanol (Fisher Chemical HPLC grade). All the methanol extracts were combined, concentrated under reduced pressure (Buchi Rotavapor R200, BUCHI, UK), and subjected to High-resolution Electrospray Ionization Liquid Chromatography Mass Spectrometry (HRESI-LC-MS, Thermo Scientific, UK) analysis.

\subsection{Molecular Network Analysis}

MSConvert software (3.0, Proteowizard, CA, US) was used to convert LCMS.RAW data to the mzXML format files. MZmine was used to preprocess the data and exported to the GNPS platform for molecular networking data analysis [37]. The GNPS analysis was achieved through the GNPS data analysis workflow using the spectral clustering algorithm [38]. Data analysis was performed using the following settings: parent mass tolerance $0.02 \mathrm{Da}$, ion tolerance $0.02 \mathrm{Da}$, minimum pairs cosine 0.7 , minimum matched peaks 6 , network TopK 10 , minimum cluster size 2 , and maximum connected component size 100. The spectral library matching was performed with a similar cosine threshold and minimum matched peaks. The spectral networks were imported into Cytoscape 3.6.1 and visualized using the force-directed layout [39].

\subsection{Spectroscopic Analysis}

HR-ESI-LC-MS was obtained using an LTQ Orbitrap LC-MS system (Thermo Scientific, UK) coupled to a Thermo Instrument HPLC system (Accela PDA detector, Accela PDA autosampler and Accela Pump) on a positive ESI mode (30,000), MS/MS resolution 7500, C18 (Sunfire $150 \times 46 \mathrm{~mm}$ column). $0.1 \%$ formic acid in water and $0.1 \%$ formic acid in acetonitrile was used for reverse-phase separation using a gradient from $0-100 \%$ in $25 \mathrm{~min}$. The instrument parameters were set as following: Capillary voltage $45 \mathrm{~V}$, spray voltage $4.5 \mathrm{kV}$, capillary temperature $200{ }^{\circ} \mathrm{C}$, auxiliary gas flow rate 10-20 arbitrary units, sheath gas flow rate 5 arbitrary units, mass range 150-2000 amu (maximum resolution 30,000×), MS scan 150-2000Da coupled with an automated full dependent MS-MS scan.

1D and 2D NMR data were obtained on a Bruker AVANCE III HD 600 MHz (Ascend ${ }^{\mathrm{TM}} 14.1$ Tesla, UK) with Prodigy TCI ${ }^{\mathrm{TM}}$ cryoprobe at $298 \mathrm{~K}$ in DMSO- $d_{6}$ and $\mathrm{CD}_{3} \mathrm{OD}$ (Goss Scientific). Trimethylsilane (TMS) was used as an internal standard.

\subsection{Fractionation of the Extract}

Fractionation of the crude methanol extract was achieved by using Strata ${ }^{\circledR}$ C18-E solid-phase extraction (SPE) $(55 \mu \mathrm{m}, 70 \AA, 20 \mathrm{~g} / 60 \mathrm{~mL})$ cartridges. The SPE column was initially washed with two column volumes (CV) of methanol and MilliQ water separately, and then, the crude sample was loaded onto the column. The column was then eluted stepwise with solvent mixtures of decreasing polarity (8CV/solvent mixture): Milli-Q $\mathrm{H}_{2} \mathrm{O}, 25 \% \mathrm{MeOH}, 50 \% \mathrm{MeOH}, 75 \% \mathrm{MeOH}, 100 \% \mathrm{MeOH}$, and $100 \% \mathrm{MeOH}$ with $0.05 \%$ trifluoroacetic acid (Acros Organics). The eluents were collected separately 
and labelled as fractions S1-S6. All the fractions were concentrated under reduced pressure (Buchi Rotavapor R200) and subjected to HR-ESI-MS analysis.

Mass spectrometry (MS) analysis was carried out in all the fractions (S1-S6) to target the MMF signalling molecules. Analysis of the HRESI-LC-MS data of fraction S3 revealed seven resolved peaks with $[\mathrm{M}+\mathrm{H}]^{+}$ions at $\mathrm{m} / \mathrm{z} 184.0967,198.1123,212.128$, respectively. Dereplication of these masses was achieved using AntiBase (2017), indicating that these molecules were previously unreported but might share a similar furan core as MMF molecules. Thus, fraction S3 was selected for further fractionation by reversed-phase semi-prep (C18 ACE $10 \mu \mathrm{M} 10 \times 250 \mathrm{~mm}$ column) HPLC (Agilent 1260 Infinity). The purification was carried out using a linear gradient from $20 \% \mathrm{H}_{2} \mathrm{O}: \mathrm{MeOH}(95: 5)$ to $100 \% \mathrm{MeOH}$ for $28 \mathrm{~min}$ with a solvent flow rate of $1.5 \mathrm{~mL} / \mathrm{min}$, to yield AHFA $\mathbf{1}(1.0 \mathrm{mg})$. Six other furan derivatives, 7-12 were identified in the same fraction by HRESI-LC-MS and molecular network analyses (Figure S9, Table S1). However, these molecules could not be isolated due to their presence in trace quantities in the extract. Compound 2-6 were isolated in the fraction S2, using a linear gradient from $10 \% \mathrm{H} 2 \mathrm{O}$ : $\mathrm{MeOH}(95: 5)$ to $100 \% \mathrm{MeOH}$ for $28 \mathrm{~min}$ with a solvent flow rate of $1.5 \mathrm{~mL} / \mathrm{min}$.

Along with 1, we also isolated cyclo-(L-Pro-Gly) 2, cyclo-(L-Pro-L-Phe) 3, cyclo-(L-Pro-L-Val) 4, cyclo-(L-Leu-Hyp) 5, and deferoxamine E 6.

AHFA 1: 1.0mg; pale yellow powder. UV $\left(\mathrm{CH}_{3} \mathrm{OH}\right): 250 \mathrm{~nm} ;{ }^{1} \mathrm{H},{ }^{13} \mathrm{C}-\mathrm{NMR}$ data, see Table 1; HRESIMS (positive mode) $m / z$ calculated $[\mathrm{M}+\mathrm{H}]^{+}=198.1125$; observed $[\mathrm{M}+\mathrm{H}]^{+}=198.1123$; $\Delta=-0.5050 \mathrm{ppm}$.

cyclo-(L-Pro-Gly) 2: $1.2 \mathrm{mg}$; white solid; ${ }^{1} \mathrm{H},{ }^{13} \mathrm{C}-\mathrm{NMR}$ data, see Figure S21, Table S2; HRESIMS (positive mode) $\mathrm{m} / z$ calculated $[\mathrm{M}+\mathrm{H}]^{+}=155.0815$; observed $[\mathrm{M}+\mathrm{H}]^{+}=155.0821 ; \Delta=2.870 \mathrm{ppm}$.

cyclo-(L-Pro-L-Phe) 3: $2.0 \mathrm{mg}$; pale yellow solid; ${ }^{1} \mathrm{H},{ }^{13} \mathrm{C}-\mathrm{NMR}$ data, see Figure S22, Table S2; $[\alpha]^{25} \mathrm{D}=-17.2\left(c\right.$ 1.0, MeOH); HRESIMS (positive mode) $\mathrm{m} / z$ calculated $[\mathrm{M}+\mathrm{H}]^{+}=245.1285$; observed $[\mathrm{M}+\mathrm{H}]^{+}=245.1276 ; \Delta=-2.631 \mathrm{ppm}$.

cyclo-(L-Pro-L-Val) 4: $2.1 \mathrm{mg}$; pale yellow solid; ${ }^{1} \mathrm{H},{ }^{13} \mathrm{C}-\mathrm{NMR}$ data, see Figure S23, Table S2; $[\alpha]^{25} \mathrm{D}=-31.0(\mathrm{c} 1.0, \mathrm{MeOH})$; HRESIMS (positive mode) $\mathrm{m} / \mathrm{z}$ calculated $[\mathrm{M}+\mathrm{H}]^{+}=197.1285$; observed $[\mathrm{M}+\mathrm{H}]^{+}=197.1284 ; \Delta=-0.5070 \mathrm{ppm}$.

cyclo-(L-Leu-Hyp) 5: $2.3 \mathrm{mg}$; yellow solid; ${ }^{1} \mathrm{H},{ }^{13} \mathrm{C}-\mathrm{NMR}$ data, see Figure S24, Table S2; $[\alpha]{ }^{25} \mathrm{D}=-11.6(c 1.0, \mathrm{MeOH})$; HRESIMS (positive mode) $\mathrm{m} / \mathrm{z}$ calculated $[\mathrm{M}+\mathrm{H}]^{+}=227.1390$; observed $[\mathrm{M}+\mathrm{H}]^{+}=227.1392 ; \Delta=-0.7040 \mathrm{ppm}$.

Deferoxamine E 6: $3.0 \mathrm{mg}$; pale yellow solid; ${ }^{1} \mathrm{H},{ }^{13} \mathrm{C}-\mathrm{NMR}$ data, see Figure S25, Table S3; HRESIMS (positive mode) $m / z$ calculated $[\mathrm{M}+\mathrm{H}]^{+}=601.3356$; observed $[\mathrm{M}+\mathrm{H}]^{+}=601.3350 ; \Delta=-1.031 \mathrm{ppm}$.

\subsection{Advanced Marfey's Experiment}

Compounds 2-5 $(0.5 \mathrm{mg})$ were hydrolysed in $6 \mathrm{~N} \mathrm{HCl}(1 \mathrm{~mL})$ for $17 \mathrm{~h}$ at $115^{\circ} \mathrm{C}$. The hydrolysate was evaporated to dryness, dissolved in $\mathrm{H}_{2} \mathrm{O}(100 \mu \mathrm{L})$, and then, treated with $1 \mathrm{M} \mathrm{NaHCO}_{3}(20 \mu \mathrm{L})$, and FDLA, fluorodinitrophenyl-5-L-leucine amide (1\% solution in acetone, $100 \mu \mathrm{L})$. The mixture was incubated at $40{ }^{\circ} \mathrm{C}$ for $1 \mathrm{~h}$. The reaction was neutralized by addition of $2 \mathrm{~N} \mathrm{HCl}(20 \mu \mathrm{L})$ and evaporated to dryness at $40{ }^{\circ} \mathrm{C}$ under a stream of dry $\mathrm{N}_{2}$. The residue was dissolved in $\mathrm{CH}_{3} \mathrm{OH}(500 \mu \mathrm{L})$ and filtered (0.45 $\mu \mathrm{m}$ PTFE) prior to HPLC-Diode Array Detection (DAD) analysis. The separation was carried out using gradient elution $\mathrm{CH}_{3} \mathrm{CN} / \mathrm{H}_{2} \mathrm{O}$ with $0.1 \%$ TFA (from $0 \%$ to $100 \%$ for $30 \mathrm{~min}$, flow rate $1.0 \mathrm{~mL} / \mathrm{min}$, UV detection $\lambda_{\max } 340 \mathrm{~nm}$ ).

The standard amino acids were derivatized with FDLA and analyzed by HPLC-DAD in the same manner as the test compounds.

\subsection{Genome Sequencing of Streptomyces sp. RK44}

The genome sequencing of Streptomyces sp. RK44 and the sequencing assembly service were provided by BGI-Shenzhen, China. A 300 bp paired-end genomic library of RK44 was prepared for Illumina sequencing. A total of 11,820,095 bp were obtained and assembled by SOAP denovo software. The assembled genome was submitted to the RAST server for annotation [40]. The open reading 
frames (ORFs) of the ahfa gene cluster was identified using the key enzymes encoded in the known $m m f$ gene cluster as a sequence query. The $16 \mathrm{~s}$ rDNA sequences and the $a h f a$ cluster has been deposited in the NCBI (MN906804).

Based on the partial 16s DNA gene sequence analysis it was identified that the strain belongs to the class Streptomyces and was most closely related to three strains with $82.49 \%$ sequence similarity: Streptomyces hoynatensis S1412, Streptomyces carpaticus NRRL B-16359, Streptomyces yeochonensis NBRC 100782. The strain formed a well-separated clade in the genus Streptomyces (Figure 4) based on the $16 \mathrm{~S}$ rRNA gene analysis, indicating that Streptomyces sp. RK44 is a new Streptomyces species (MEGA 7, Neighbor-Joining method) [41,42]. The optimum $\mathrm{pH}$ for growth was determined to be 7.2. The DNA $\mathrm{G}+\mathrm{C}$ content of the strain was determined to be $71.4 \mathrm{~mol} \%$.

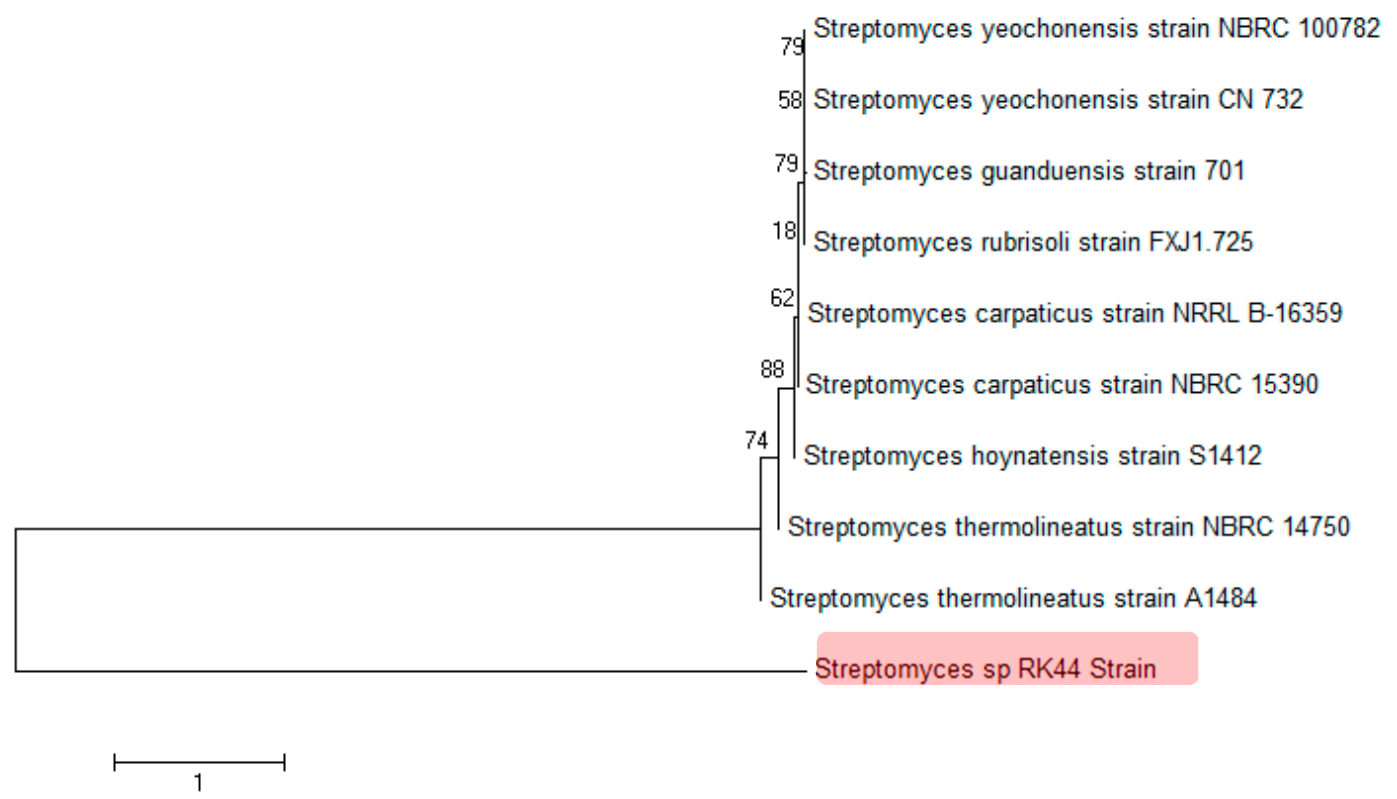

Figure 4. Phylogenetic analysis of $16 \mathrm{~S}$ rDNA sequences of Streptomyces sp. RK44 and other known Streptomyces species, indicating that Streptomyces sp. RK44 is a new Streptomyces species.

\subsection{Sequence Similarity Network}

The sequence similarity network (Figure 2) of the biosynthetic gene clusters of Streptomyces sp. Rk44 and Streptomyces coelicolor A3(2) was constructed by all-to-all BLASTP comparison of sequences found in strains containing essential biosynthetic genes involved in the MMF and AHFA biosynthesis. Each node represents a gene and each edge represents the BLASTP pairwise comparison (E-value $>1 \times 10^{-10}$ ) between two gene sequences. The results generated were visualized using Cytoscape 3.6.1. The genes, $m m f L, H, P$, are coloured with red, green, and blue, respectively. Other genes in the clusters were coloured with grey [28].

\subsection{Anti-Proliferative/Cytotoxicity Test}

The anti-proliferative activity of AHFA 1 was tested on the human melanoma A2058 cancer cell line (American Type Culture Collection (ATCC) CRL-11147 ${ }^{\mathrm{TM}}$, Manassas, VA, USA). Cell lines were seeded in 96-well-microtitre plates (Nunc, Thermo Fisher Scientific, NY, USA) at 2000 cells/well in Dulbecco's Modified Eagle Medium (DMEM, Thermo Fisher Scientific, USA) with fetal bovine serum (10\%, FBS, Sigma Aldrich, USA) and gentamicin $(10 \mu \mathrm{g} / \mathrm{mL}$, Sigma Aldrich, USA). Cells were grown at $37^{\circ} \mathrm{C}$ in a humidified atmosphere of $5 \% \mathrm{CO}_{2}$ and maintained at low passage.

Toxicity assay was tested on the lung normal cell (ATCC CCL-171).Cell lines were seeded in 96-well-microtitre plates (Nunc, Thermo Fisher Scientific, CA, USA) at 4000 cells/well in DMEM with 
FBS $(10 \%)$ and gentamicin $(10 \mu \mathrm{g} / \mathrm{mL})$. Cells were grown at $37^{\circ} \mathrm{C}$ in a humidified atmosphere of $5 \%$ $\mathrm{CO}_{2}$ and maintained at low passage.

Cells were incubated for $24 \mathrm{~h}$ before AHFA 1 was added and thereafter incubated for $72 \mathrm{~h}$. Cell viability was determined by a colorimetric 3-(4,5-dimethylthiazol-2-yl)-5-(3 carboxymethoxyphenyl)-2-(4-sulfophenyl)-2H-tetrazolium (MTS) assay. At the end of the exposure time, $10 \mu \mathrm{L}$ Cell Titer $96^{\circledR}$ Aqueous One Solution Reagent (Promega, Madison, WI, USA) was added to each well. Results were measured after $1 \mathrm{~h}$ at $485 \mathrm{~nm}$. The dose-dependent response of AHFA 1 $(100 \mathrm{ng} / \mathrm{mL}, 1,2.5,5,10,12.5,25$, and $50 \mu \mathrm{g} / \mathrm{mL})$ was tested in triplicates.

\subsection{Antibacterial Assay}

Minimum inhibitory concentrations (MIC) were determined using a conventional broth dilution assay in accordance with standards recommended by the National Committee for Clinical Laboratory Standards (NCCLS) [43]. Gram-negative bacteria Escherichia coli (ATCC 25922) and Pseudomonas aeruginosa (ATCC 27853) were used as test organisms. All bacteria were cultured in Mueller-Hinton broth. The assays were performed in 96-well plates (Nunc, Thermo Fisher Scientific, NY, USA), wherein a $50 \mu \mathrm{L}$ suspension (log phase) of actively growing bacteria was incubated overnight at $37^{\circ} \mathrm{C}$ and then treated with $50 \mu \mathrm{L}$ of the test extract (final concentration of $50 \mu \mathrm{g} / \mathrm{mL}$, for the three biological triplicates). The negative control comprised the growth media and Milli-Q water, while the positive control consisted of the bacteria plus Milli-Q water. The absorbance was recorded after $24 \mathrm{~h}\left(\mathrm{OD}_{600}\right)$ in a Victor3 multilabel plate reader. The growth medium appeared clear in wells where the test compound prevented the growth or killed the bacteria; otherwise, it was cloudy. Activity threshold was set below $0.05\left(\mathrm{OD}_{600}\right)$.

\subsection{Plasmodium Falciparum 3D7 Lactate Dehydrogenase Assay}

The antiplasmodial activities of 1-6 were assessed by lactate dehydrogenase assay using Plasmodium falciparum 3D7 as the test organism. The assay was performed according to the method previously described by Pérez-Moreno et al., 2016 [36], in triplicate using a sixteen points dose-response curve (1/2 serial dilutions) with concentrations ranging from $50 \mu \mathrm{M}$ to $1.5 \mathrm{nM}$ to determine the $\mathrm{IC}_{50}$ of the pure compounds. Chloroquine was used as the standard reference.

\section{Conclusions}

Herein, we report the discovery of AHFA 1 from the novel soil bacterium Streptomyces sp. RK44. The structure of 1 was deduced by analysis of the HRESIMS, UV, 1D, and 2D NMR, and identified as a new AHFA-type natural product. Seven AHFA analogues, 7-12 and siderophores 13-18 were tentatively identified in the extract of RK44 by HRESIMS and GNPS molecular network analyses. A putative AHFA biosynthetic pathway was proposed for 1 . AHFA 1 displayed antiproliferative activity against melanoma $\mathrm{A} 2058$ cells $\left(\mathrm{EC}_{50}=89.6 \mu \mathrm{M}\right)$. Albeit weak, this represents the first report of such activity amongst MMF molecules. Five other known metabolites, cyclo-(L-Pro-Gly) 2, cyclo-(L-Pro-L-Phe) 3, cyclo-(L-Pro-L-Val) 4, cyclo-(L-Leu-Hyp) 5, and deferoxamine E 6 were isolated and structurally characterized, one of which, DFO-E 6 displayed potent activity against $P$. falciparum 3D7 $\left(\mathrm{IC}_{50}=1.08 \mu \mathrm{M}\right)$.

Supplementary Materials: The supplementary materials are available online.

Author Contributions: Q.F., R.E., F.A., G.P.-M., F.R., J.H., L.W., F.M., H.D. formal analysis and investigation. H.D., K.K., J.H.A. funding acquisition and methodology. Q.F., F.M., H.D. writing original draft. H.D., J.H.A., F.R., K.K. review and editing. H.D. supervision and project administration. All authors have read and agreed to the published version of the manuscript. 
Funding: Q.F. is grateful to the University of Aberdeen Elphinstone Scholarship and Scottish Funding Council/ScotCHEM for financial support through the PEER/PERCE Funding. FM thanks the University of the Philippines for the Faculty, Reps and Staff Development Program (FRAS DP) for the PhD grant fellowship. HD and KK thank the financial supports of Leverhulme Trust-Royal Society Africa award (AA090088) and the jointly funded UK Medical Research Council-UK Department for International Development (MRC/DFID) Concordat agreement African Research Leaders Award (MR/S00520X/1).

Conflicts of Interest: The authors declare no conflict of interest.

\section{References}

1. Eliakim-Raz, N.; Lador, A.; Leibovici-Weissman, Y.; Elbaz, M.; Paul, M.; Leibovici, L. Efficacy and Safety of Chloramphenicol: Joining the Revival of old Antibiotics? Systematic Review and Meta-Analysis of Randomized Controlled Trials. J. Antimicrob. Chemother. 2014, 70, 979-996. [CrossRef]

2. Falagas, M.E.; Vouloumanou, E.K.; Samonis, G.; Vardakas, K.Z. Fosfomycin-Microbiology Review. Clin. Microbiol. Rev. 2016, 29, 321-347. [CrossRef]

3. Vons, C.; Barry, C.; Maitre, S.; Pautrat, K.; Leconte, M.; Costaglioli, B.; Karoui, M.; Alves, A.; Dousset, B.; Valleur, P.; et al. Amoxicillin Plus Clavulanic Acid Versus Appendicectomy for Treatment of Acute Uncomplicated Appendicitis: An Open-Label, Non-Inferiority, Randomised Controlled Trial. Lancet 2011, 377, 1573-1579. [CrossRef]

4. Kitani, S.; Miyamoto, K.T.; Takamatsu, S.; Herawati, E.; Iguchi, H.; Nishitomi, K.; Uchida, M.; Nagamitsu, T.; Omura, S.; Ikeda, H.; et al. Avenolide, a Streptomyces Hormone Controlling Antibiotic Production in Streptomyces Avermitilis. Proc. Natl. Acad. Sci. USA 2011, 108, 16410-16415. [CrossRef]

5. Maglangit, F.; Fang, Q.; Leman, V.; Soldatou, S.; Ebel, R.; Deng, H. Accramycin A, a New Aromatic Polyketide, from the Soil Bacterium, Streptomyces sp. MA37. Molecules 2019, 24, 3384. [CrossRef]

6. Maglangit, F.; Fang, Q.; Kyeremeh, K.; Sternberg, J.M.; Ebel, R.; Deng, H. A Co-Culturing Approach Enables Discovery and Biosynthesis of a Bioactive Indole Alkaloid Metabolite. Molecules 2020, 25, 256. [CrossRef] [PubMed]

7. Wang, M.; Carver, J.J.; Phelan, V.V.; Sanchez, L.M.; Garg, N.; Peng, Y.; Nguyen, D.D.; Watrous, J.; Kapono, C.A.; Luzzatto-Knaan, T.; et al. Sharing and community curation of mass spectrometry data with Global Natural Products Social Molecular Networking. Nat. Biotechnol. 2016, 34, 828-837. [CrossRef] [PubMed]

8. Santen, J.; Van, A.; Jacob, G.; Singh, A.L.; Aniebok, V.; Balunas, M.J.; Bunsko, D.; Neto, F.C.; Castaño-Espriu, L.; Chang, C.; et al. The Natural Products Atlas: An Open Access Knowledge Base for Microbial Natural Products Discovery. ACS Cent. Sci. 2019. [CrossRef] [PubMed]

9. Pence, H.E.; Williams, A. Chemspider: An online chemical information resource. J. Chem. Educ. 2010, 87, 1123-1124. [CrossRef]

10. Ito, T.; Masubuchi, M. Dereplication of Microbial Extracts and Related Analytical Technologies. J. Antibiot. (Tokyo) 2014, 67, 353-360. [CrossRef] [PubMed]

11. Crüsemann, M.; O’Neill, E.C.; Larson, C.B.; Melnik, A.V.; Floros, D.J.; Da Silva, R.R.; Jensen, P.R.; Dorrestein, P.C.; Moore, B.S. Prioritizing Natural Product Diversity in a Collection of 146 Bacterial Strains Based on Growth and Extraction Protocols. J. Nat. Prod. 2017, 80, 588-597. [CrossRef] [PubMed]

12. Corre, C.; Song, L.; O'Rourke, S.; Chater, K.F.; Challis, G.L. 2-Alkyl-4-hydroxymethylfuran-3-carboxylic acids, Antibiotic Production Inducers Discovered by Streptomyces Coelicolor Genome Mining. Proc. Natl. Acad. Sci. USA 2008, 105, 17510-17515. [CrossRef] [PubMed]

13. Schuster, M.; Joseph Sexton, D.; Diggle, S.P.; Peter Greenberg, E. Acyl-Homoserine Lactone Quorum Sensing: From Evolution to Application. Annu. Rev. Microbiol. 2013, 67, 43-63. [CrossRef] [PubMed]

14. Sidda, J.D.; Poon, V.; Song, L.; Wang, W.; Yang, K.; Corre, C. Overproduction and Identification of Butyrolactones SCB1-8 in the Antibiotic Production Superhost: Streptomyces M1152. Org. Biomol. Chem. 2016, 14, 6390-6393. [CrossRef]

15. Du, Y.L.; Shen, X.L.; Yu, P.; Bai, L.Q.; Li, Y.Q. Gamma-Butyrolactone Regulatory System of Streptomyces Chattanoogensis Links Nutrient Utilization, Metabolism, and Development. Appl. Environ. Microbiol. 2011, 77, 8415-8426. [CrossRef]

16. Bhasin, S.; Modi, H.A. Optimization of Fermentation Medium for the Production of Glucose Isomerase Using Streptomyces sp. SB-P1. Biotechnol. Res. Int. 2012, 2012, 1-10. [CrossRef] 
17. Li, X.; Dobretsov, S.; Xu, Y.; Xiao, X.; Hung, O.; Qian, P.Y. Antifouling Diketopiperazines Produced by a Deep-Sea Bacterium, Streptomyces Fungicidicus. Biofouling 2006, 22, 201-208. [CrossRef]

18. Campo, V.L.; Duarte, M.C.T.; Bastos, J.K. Diketopiperazines Produced by an Aspergillus Fumigatus Brazilian Strain. J. Braz. Chem. Soc. 2005, 16, 1448-1453.

19. Lee, S.R.; Beemelmanns, C.; Tsuma, L.M.M.; Clardy, J.; Cao, S.; Kim, K.H. A New Diketopiperazine, cyclo(D-trans-Hyp-L-Leu) from a Kenyan Bacterium Bacillus Licheniformis LB 8CT. Nat. Prod. Commun. 2016, 11, 461-463. [CrossRef]

20. Alshaibani, M.; Jalil, J.; Sidik, N.; Ahmad, S.; Kamal, N.; Edrada-Ebel, R.; MohamadZin, N. Isolation, Purification and Characterization of five Active Diketopiperazine Derivates from Endophytic Strptomyces SUK 25 with Antimicrobial and Cytotoxic Activities. J. Microbiol. Biotechnol. 2017, 27, 1-22.

21. Nishanth Kumar, S.; Mohandas, C.; Siji, J.V.; Rajasekharan, K.N.; Nambisan, B. Identification of Antimicrobial Compound, Diketopiperazines, from a Bacillus sp. N Strain Associated with a Rhabditid Entomopathogenic Nematode against Major Plant Pathogenic Fungi. J. Appl. Microbiol. 2012, 113, 914-924. [CrossRef] [PubMed]

22. Maglangit, F.; Tong, M.H.; Jaspars, M.; Kyeremeh, K.; Deng, H. Legonoxamines A-B, Two New Hydroxamate Siderophores from the Soil Bacterium, Streptomyces sp. MA37. Tetrahedron Lett. 2019, 60, 75-79. [CrossRef]

23. Yamanaka, K.; Oikawa, H.; Ogawa, H.O.; Hosono, K.; Shinmachi, F.; Takano, H.; Sakuda, S.; Beppu, T.; Ueda, K. Desferrioxamine E Produced by Streptomyces Griseus Stimulates Growth and Development of Streptomyces Tanashiensis. Microbiology 2005, 151, 2899-2905. [CrossRef] [PubMed]

24. Meiwes, J.; Fiedler, H.P.; Zähner, H.; Konetschny-Rapp, S.; Jung, G. Production of Desferrioxamine E and New Analogues by Directed Fermentation and Feeding Fermentation. Appl. Microbiol. Biotechnol. 1990, 32, 505-510. [CrossRef]

25. Corre, C.; Haynes, S.W.; Malet, N.; Song, L.; Challis, G.L. A Butenolide Intermediate in Methylenomycin Furan Biosynthesis is Implied by Incorporation of Stereospecifically 13C-Labelled Glycerols. Chem. Commun. 2010, 46, 4079-4081. [CrossRef] [PubMed]

26. Weber, T.; Blin, K.; Duddela, S.; Krug, D.; Kim, H.U.; Bruccoleri, R.; Lee, S.Y.; Fischbach, M.A.; Müller, R.; Wohlleben, W.; et al. AntiSMASH 3.0-A Comprehensive Resource for the Genome Mining of Biosynthetic Gene Clusters. Nucleic Acids Res. 2015, 43, W237-W243. [CrossRef] [PubMed]

27. Sayers, E.W.; Agarwala, R.; Bolton, E.E.; Brister, J.R.; Canese, K.; Clark, K.; Connor, R.; Fiorini, N.; Funk, K.; Hefferon, T.; et al. Database Resources of the National Center for Biotechnology Information. Nucleic Acids Res. 2019, 47, D23-D28. [CrossRef]

28. Zallot, R.; Oberg, N.O.; Gerlt, J.A. 'Democratized' Genomic Enzymology Web Tools for Functional Assignment. Curr. Opin. Chem. Biol. 2018, 47, 77-85. [CrossRef]

29. Horinouchi, S.; Beppu, T. A-factor and Streptomycin Biosynthesis in Streptomyces Griseus. Antonie Van Leeuwenhoek 1993, 64, 177-186. [CrossRef]

30. Davis, J.B.; Bailey, J.D.; Sello, J.K. Biomimetic Synthesis of a New Class of Bacterial Signaling Molecules. Org. Lett. 2009, 11, 2984-2987. [CrossRef]

31. Alberti, F.; Leng, D.J.; Wilkening, I.; Song, L.; Tosin, M.; Corre, C. Triggering the Expression of a Silent Gene Cluster from Genetically Intractable Bacteria Results in Scleric Acid Discovery. Chem. Sci. 2019, 10, 453-463. [CrossRef] [PubMed]

32. Gordeuk, V.R.; Thuma, P.E.; Brittenbam, G.M. Iron Chelation Therapy for Malaria. Adv. Exp. Med. Biol. 1994, 356, 371-383. [PubMed]

33. Rotheneder, A.; Fritsche, G.; Heinisch, L.; Heggemann, S.; Larcher, C.; Möllmann, U.; Weiss, G. Effects of Synthetic Siderophores on Proliferation of Plasmodium falciparum in Infected Human Erythrocytes. Antimicrob. Agents Chemother. 2013, 46, 9-13.

34. Ferrer, P.; Tripathi, A.K.; Clark, M.A.; Hand, C.C.; Rienhoff, H.Y.; Sullivan, D.J. Antimalarial Iron Chelator, FBS0701, Shows Asexual and Gametocyte Plasmodium Falciparum Activity and Single Oral Dose Cure in a Murine Malaria Model. PLoS ONE 2012, 7, 1-7. [CrossRef]

35. Pradines, B.; Rolain, J.M.; Ramiandrasoa, F.; Fusai, T.; Mosnier, J.; Rogier, C.; Daries, W.; Baret, E.; Kunesch, G.; Le Bras, J.; et al. Iron Chelators as Antimalarial Agents: In Vitro Activity of Dicatecholate against Plasmodium falciparum. J. Antimicrob. Chemother. 2002, 50, 177-187. [CrossRef] 
36. Pérez-Moreno, G.; Cantizani, J.; Sánchez-Carrasco, P.; Ruiz-Pérez, L.M.; Martín, J.; El Aouad, N.; Pérez-Victoria, I.; Tormo, J.R.; González-Menendez, V.; González, I.; et al. Discovery of new Compounds Active against Plasmodium Falciparum by High Throughput Screening of Microbial Natural Products. PLOS ONE 2016, 11, 1-16. [CrossRef]

37. Pluskal, T.; Castillo, S.; Villar-Briones, A.; Orešič, M. MZmine 2: Modular Framework for Processing, Visualizing, and Analyzing Mass Spectrometry-based Molecular Profile Data. BMC Bioinformatics 2010, 11, 395. [CrossRef]

38. Pylayeva-Gupta, Y. The Spectral Networks Paradigm in High Throughput Mass Spectrometry. Bone 2011, 23, $1-7$.

39. Shannon, P.; Markiel, A.; Ozier, O.; Baliga, N.S.; Wang, J.T.; Ramage, D.; Amin, N.; Schwikowski, B.; Ideker, T. Cytoscape: A Software Environment for Integrated Models of Biomolecular Interaction Networks. Genome Res. 2003, 2498-2504. [CrossRef]

40. Aziz, R.K.; Bartels, D.; Best, A.A.; DeJongh, M.; Disz, T.; Edwards, R.A.; Formsma, K.; Gerdes, S.; Glass, E.M.; Kubal, M.; et al. The RAST Server: Rapid Annotations Using Subsystems Technology. BMC Genomics 2008, 9, 75. [CrossRef]

41. Saitou, N.; Nei, M. The Neighbor-Joining Method: A New Method for Reconstructing Phylogenetic Trees. Mol. Biol. Evol. 1987, 4, 406-425. [PubMed]

42. Kumar, S.; Stecher, G.; Tamura, K. MEGA7: Molecular Evolutionary Genetics Analysis Version 7.0 for Bigger Datasets. Mol. Biol. Evol. 2016, 33, 1870-1874. [CrossRef] [PubMed]

43. Carpenter, D.E.; Karen Anderson Diane Citron, C.M.; JoAnn Dzink-Fox, B.L.; Meredith Hackel, M.; Jenkins, S.G.; Cindy Knapp, F.; Laura Koeth, M.; Audrey Schuetz, M.N.; Hannah Wexler, D. Methods for Antimicrobial Susceptibility Testing of Anaerobic Bacteria, 9th ed.; CLSI standard M11; Clinical and Laboratory Standards Institute: Wayne, PA, USA, 2018; pp. 11-19.

Sample Availability: Samples of the compounds are not available from the authors.

(C) 2020 by the authors. Licensee MDPI, Basel, Switzerland. This article is an open access article distributed under the terms and conditions of the Creative Commons Attribution (CC BY) license (http://creativecommons.org/licenses/by/4.0/). 